\title{
A Review of Battery Exchange Technology for Refueling of Electric Vehicles
}

\author{
C. Arthur MacCarley \\ California Polytechnic State University, San Luis Obispo, California, USA
}

Copyright () 1999 Society of Automotive Engineers, Inc.

\begin{abstract}
The limited energy storage and long recharge time and of electric vehicle batteries have motivated several alternatives to in-vehicle slow charging. Solutions generally fall into three categories: (1) fast charging, in which batteries are charged in-vehicle at an accelerated rate, (2) battery material reloading or refueling, in which the energy-carrying elements of the battery are physically replaced or replenished, and (3) battery interchange, involving the complete exchange of the battery pack, usually with the aid of some semiautomated mechanism. Among these options, the last, battery interchange, has tended to receive the least industry attention, but has been an expansive topic of invention and novel deployment.
\end{abstract}

This paper reviews battery interchange technology, including discussion of advantages and limitations, the history of battery exchange concepts and implementations, the many possible interchange configurations, novel automation mechanisms, key patents, safety and regulatory considerations, and the economics of fleet and public deployments. Selected case histories will be presented dating from the late 1800's through the mid-1990's. Commercial and technical impediments will be identified. The full cost of battery interchange, including incremental vehicle costs and infrastructure costs will be assessed, and this will serve as a basis for comparison with slow and fast charging options for fleet and private vehicle operations. Battery interface and configuration standards will be discussed as possible means for facilitating wider-scale deployment. The results of a survey of the EV industry and user community on the perceived viability and acceptability of EV battery interchange will be presented.

\section{INTRODUCTION}

Since the "Golden Age" of electric vehicles, between 1895 and 1905, through the present renaissance of EVs, engineers have sought practical means for overcoming the energy storage limitations and long recharge times of electrochemical batteries. Despite over 100 years of research on improved batteries, and many incremental improvements, these limitations remain today, and are considered the primary reasons for the lack of widespread use of electric cars, trucks and buses. The concept of real-time battery swapping, exchange or interchange, in which vehicle batteries are replaced rather than recharged in-vehicle, has often been considered as a practical means for reducing the refueling time and effectively extending the range of battery-electric vehicles. In situations in which it is practical, battery interchange may be considered an alternative to high-rate in-vehicle battery charging, hybrid power systems, fuel cells, or exchange of the entire vehicle. Any advantages relative to these options must, however, be considered against the significant materials handling and support infrastructure requirements for vehicular battery exchange. The technical challenges of mechanizing the removal, replacement and off-vehicle charging (or reactivation) have inspired a wide range of novel solutions, with various degrees of success. Historically, only isolated implementations have been demonstrated.

\section{BACKGROUND}

The development of battery-electric vehicles and related componentry may be best described as an evolutionary rather than a revolutionary process with few remarkable improvements, but a steady stream of engineering refinements.

According to Ernest Henry Wakefield [Wakefield 94], in a well-researched history of the electric automobile, the first known battery-electric propulsion automobile was assembled in 1881 by electrical engineer Gustave Trouve of France. The tricycle configured vehicle used lead acid storage batteries for energy storage, which had been invented in 1859 by Gaston Plante, also of France. At the International Exhibition of Electricity held in Paris in 1881, Trouve's electric tricycle, as well as an electric boat and a model dirigible powered by an electric motor were exhibited.

In England, the second known electric automobile was constructed by Professors W. E. Ayrton and John Perry of London in the mid-1880's. The Ayrton and Perry tricycle used lead-acid batteries also, and incorporated a number of other automotive electrical features that would not appear again for decades: dual electric arc headlights, power and speed control via series battery 
switching, a voltmeter and ammeter for estimation of battery charge remaining, friction brakes, and an all-gear transmission. The first automotive World Land Speed Record competition was held between two electric vehicles in 1899. The winner was a bullet-shaped vehicle constructed by Jenatzy Jamais Contente, with a record speed of $65 \mathrm{MPH}$ [Karen79]. This vehicle also has the distinction of being the first automobile to include consideration of aerodynamics in its design, a concept not significantly incorporated again until at least thirty years later [Collie79.1].

At the turn of the century, "electrics" dominated over steam and hydrocarbon combustion alternatives in the fledgling automotive market, due to their quiet and clean operation, and superior performance. By the turn of the century, a veritable explosion of manufacturing entities for electric vehicles had occurred in both Europe and the United States. By 1900, over 1000 electric-powered taxis (called hacks) were in service in Paris. In 1903, automobile registrations in New York State included a majority of electric vehicles, with the Locomobile Company of America alone claiming to have sold over 4,000 vehicles, as reported in a 1903 edition of the periodical "Horseless Age" [Wakefield 94].

What is most remarkable about these early electric automobiles is how little they differ in technology, performance and range from the present state of the art. The lead-acid storage battery, which powered the first electric automobile, is still the battery of choice today. The nickel-iron system, with a higher energy density but lower power rating than lead-acid, powered electric vehicles as early as 1890, but remains classified as an "advanced battery technology" by the U.S. Department of Energy. Indeed, Thomas Edison, an active promoter of electric autos, maintained until his death that a better battery is "just around the corner." That the limitations of
EVs were due to battery technology was recognized and documented from the time of the first commercial EV's. From America Adopts the Automobile, 1885-1910 by [Flink 70] and reprinted in [Hamilton 80.1]:

"The weight of storage batteries remained inordinately heavy for the horsepower generated, and they still deteriorated rapidly. For years Thomas Edison had been rashly promising that he would soon develop an improved storage battery that would make the electric more practical than the gasoline automobile. At first Edison had been taken seriously, but by 1908 he was being ridiculed for his persistent failures." As Motor Age commented in 1908, "Mr. Edison's bunk has come to be somewhat of a joke -- a real joke."

The need for alternative solutions to the problem of inadequate range and long recharge time would be recognized and addressed soon after the first electric automobiles appeared on the dirt roads of Europe and America. The first practical solutions involved various methods of battery exchange. Figure 1, reprinted from [Wakefield94], shows a lithograph of a French Electromobile Hack of 1899 refueling at the Rue Cardinet Charging Station in Paris, which serviced up to 200 of these hacks at a time.. The battery pack on this vehicle was suspended underneath the carriagework, and was removed and replaced with a fresh unit using a lateral trolley system. Battery packs were charged off the vehicles, and scheduled for recharging in such a way as to optimally utilize the output of the coal-fired generators which provided the electric power for the facility. A similar vehicle configuration and facility was developed a few years earlier in 1896, by the Morris and Salom Company, servicing a somewhat smaller taxi fleet in New York City, as shown in Figure 2, also reprinted from [Wakefield 94].

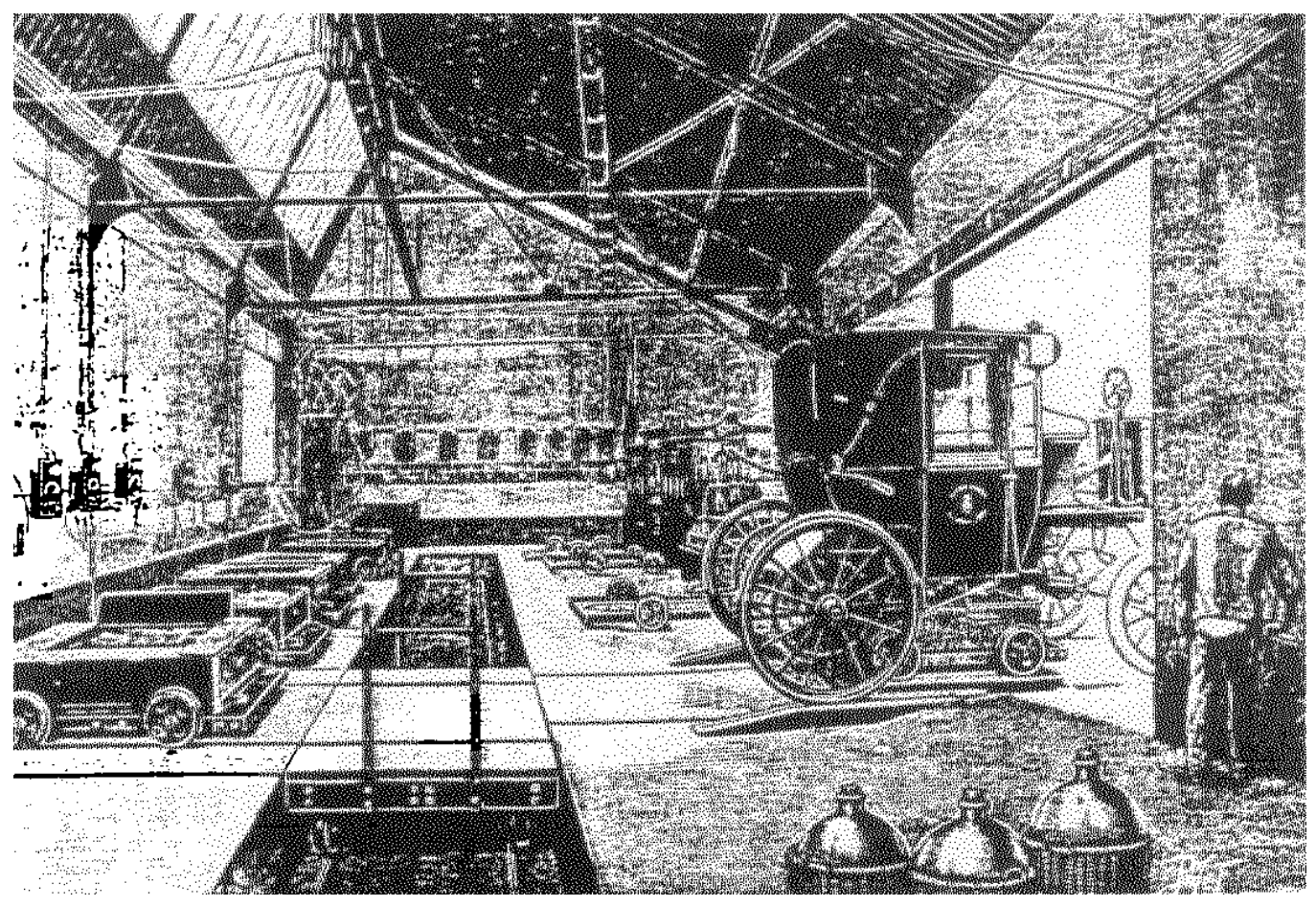

Figure 1. Rue Cardinet Battery Exchange and Charging station, Paris, 1899, Scientific American 1899, reprinted from [Wakefield 94]. 


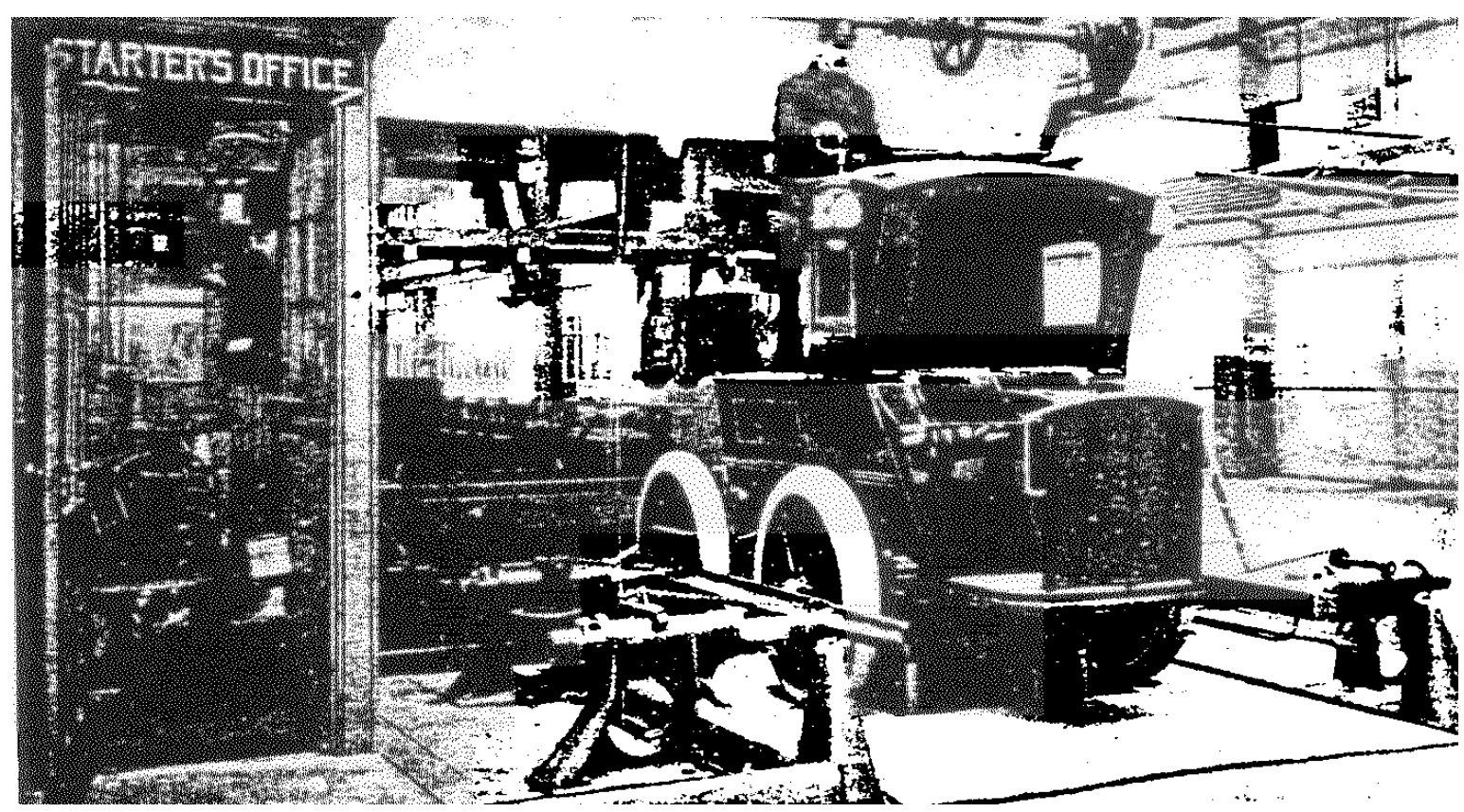

Figure 2. New York City Electric Taxi and Charging Station, 1896, from [Wakefield 94].

After about 1920, battery electric vehicles faded from the scene in the shadow of the rapidly improved internal combustion engine, and the establishment of a viable fuel distribution network [Hamilton80.1]. Electric propulsion remained popular only in applications for which zero emissions or quiet or intermittent operation was imperative: indoor-operated vehicles such as forklifts, mining vehicles, and golf cars. With the lack of incentive for improved batteries, or alternatives to improved batteries, few new patents related to electric automobiles appeared between approximately 1920 and 1970. Both World Wars punctuated this lull briefly, with a recognized need for improved batteries for submarines, to enable extended submerged cruising.

With the first peacetime petroleum shortages in the USA in the early 1970's came the motivation for government funding to support energy independence, as well as interest in reducing automotive pollution. Local gasoline shortages in 1974 and 1979 precipitated large scale funding of research and testing of electric vehicles and advanced batteries by the U.S. Energy Research and Development Administration. Alternative fuels and electric vehicle research languished again in the 1980's with the decline in petroleum prices. Interest in electric transportation was revived again in 1990, following renewed concerns about urban air quality and energy independence. In the USA, the State of California has taken the lead in the air quality area with legislation passed in 1993 which requires a progressively increasing percentage of new vehicles sold in the state ( $2 \%$ by $1998,10 \%$ by 2003 ) to be "zero emission vehicles" REVs). The requirements of this law were substantially reduced in 1996 following appeals by auto manufacturers.

Range limitations seem to drive consumer reluctance to purchase EVs. For example, in 1995 Ed Kwik <AHDNN1A.LZ26Z1@GMEDS.COM> posted an article to an Internet EV forum describing the results of the General Motors "PrEView" campaign in which 72 drivers were given the opportunity to drive a GM Impact, considered at the time one of the most advanced EVs available:

"GM IMPACT PREVIEW GIVES GLIMPSE INTO PUBLIC REACTION TO EVs. Los Angeles-area test drivers believe electric vehicles (EVs) hold the promise of a viable transportation option in the future, but recommend improvement in vehicle range and public remote charging infrastructure, according to the first results from the GM PrEView Drive program."

Modern deep-cycle lead-acid batteries today are estimated to have about twice the specific energy density, and provide about twice the vehicle range as their 100-year-old predecessors. But today, as in 1881, approximately $40 \%$ of the mass of a typical electric vehicle is typically assigned to the batteries.

Sporadic but intense research has been in progress since approximately 1973 on advanced batteries as replacements for the venerable lead-acid battery. In 1990, the US Advanced Battery Consortium, a group of battery and electric vehicle manufacturers and electric utilities, was formed under the auspices of the Electric Power Research Institute (EPRI) and co-funded by the U.S. Department of Energy and the top three U.S. auto makers. In 1992 alone, this consortium funded \$54 million in battery research and development [Risser 92.1]. Engineering improvements have continued incrementally, with configuration changes netting the greatest improvements in cost-effectiveness [Riezenman95]. Yet, to date, the lead-acid battery still powers the large majority of commercially available EVs [GM92].

The problem with storage of energy in an electrochemical battery is put into perspective when one considers that one U.S. gallon $(3.78 \mathrm{~L})$ of unleaded gasoline with a mass of under slightly three kilograms $(\mathrm{Kg})$, contains 34 kilowatt-hours (kWh) of usable energy, 
a specific energy density of approximately 11,300 Watthours per $\mathrm{kg}(\mathrm{Wh} / \mathrm{kg})$. By comparison, a typical state-ofthe-art lead-acid deep-cycle battery contains only about $25 \mathrm{Wh} / \mathrm{kg}$, a factor of 450 less than gasoline. Some improvement to this dismal figure is realized by comparing the relatively poor (typically 25\%) energy conversion efficiency of an internal combustion engine (ICE) with the high efficiency of modern electric drive systems (over 90\%). In addition, the overall use-cycle efficiency of an EV is superior to an ICE vehicle by a factor of two or more in urban driving, since an ICE must remain idling at stops, and cannot recover braking energy, while an EV is powered only when torque is required, and can recover some energy during deceleration if regenerative braking is implemented. With these factors included, the effective energy density of gasoline compared with a lead-acid battery shrinks to a factor of approximately 62 , which is still unattractive. Recently developed advanced battery chemistries have demonstrated specific energy densities over 1000 Wh/kg, but they remain excessively costly compared with lead-acid batteries.

In the absence of a major breakthrough in battery technology, only two practical means for extending the daily range of battery-electric vehicles have been recognized: fast charging of batteries in-vehicle or battery interchange, the complete exchange of a discharged battery package with a charged one. Hybrid propulsion, in which an ICE drives a generator to supply some or all of the motive energy for an otherwise electric propulsion vehicle, is considered another practical alternative, but not a true zero emission vehicle.

Normal recharge times for lead-acid batteries vary from 10 hours for golf-cart type lead-acid batteries [Jones81], to 2-3 hours for the advanced lead-acid batteries in the GM Impact. Fast charging implies the accelerated charging of a battery on-board the vehicle, at least to some partial depth of charge. Only within the past decade have successful attempts been made to accelerate the charging of traction batteries without damage to the battery. Perhaps fast charging is a misnomer, since, except for experimental situations, fast partial recharges typically require a minimum of fifteen minutes - still not in the range of the refueling time of an ICE vehicle. Another concern is that the electric power required to fast charge a fixed vehicle battery is large. While it would be overly simplistic to consider a single isolated fast-charge installation, it is worthwhile to put the power requirement into perspective. If a typical 20 kWh battery in a small EV is charged from a 220VAC supply to $40 \%$ capacity in fifteen minutes with an efficiency of $75 \%$, an RMS current of 194 Amps at 220 Volts, or $42.7 \mathrm{~kW}$, would be required. This is nearly equivalent to the entire capacity of a typical $200 \mathrm{Amp}$ service for a larger new home. The potential impact of the high intermittent demands of fast charging on the utility grid remains to be studied. Transfer of power from a stationary ballast battery overcomes the high utility current demand, but nearly doubles the amortized cost due to the incremental expenditure of the stationary battery, measured in charge/recharge cycles.

Fast charging has some clear advantages in terms of mechanization. It does not constrain the vehicle design to require external access to the batteries; batteries can be placed optimally in the vehicle to best utilize space, rather than contained in a single or a few modules; no external mechanical equipment is required; and the familiar concept of "filling-up" the vehicle with energy by attaching a hose or connector is retained. Fast charging technology has been the topic of intense research. Recent breakthroughs have been reported, including that of Nissan (Japan) with their "Super Quick Charge System" utilizing either nickel-cadmium (NiCd) or leadacid ( $\mathrm{Pb}$-acid) batteries or both. They report the ability to charge NiCd batteries to $40 \%$ capacity in 6 minutes, or $\mathrm{Pb}$-acid batteries to the same capacity in 12 minutes [Mader91]. Industrial 440 Volt three phase electric service is required for the charger, which is about the size of an automated teller kiosk. Alternative battery chemistries are known to have significantly reduced recharge times, among them nickel-metal hydride batteries, which are reported to be quick-chargeable in as little as 15 minutes [GM92].

Accelerated rates of recharging are not without consequences, however. Batteries of virtually all chemistries which are not specifically designed to accept high rates of charge are overheated or progressively damaged by excessive charge rates. Regardless of battery type or configuration, energy transfer efficiency drops significantly with increasing rate of charge, partially nullifying the energy efficiency benefits of the EV. Batteries designed specifically to accept rapid recharge rates typically have compromised cycle life and/or energy density. In the Nissan FEV (Future Electric Vehicle), specially designed NiCd batteries with reduced internal resistance are used, along with provision for forced-air cooling of the battery enclosure [Wyczalek92]. Reduced internal resistance, however, reduces the battery "shelf life" due to internal discharge regardless of load.

Battery exchange, performed in "real-time" by some automated mechanism, involves the physical exchange of the vehicle battery with a charged one, in a short period of time. We will distinguish the "automated highspeed exchange" feature of this update of an old idea by referring to it henceforth as rapid battery interchange (RBI). Although many semi-automated mechanisms for $\mathrm{RBI}$ have been demonstrated, our research has found no fully-automated mechanism for road-going vehicles demonstrated to date.

For comparison of energy transfer rates, we observe that gasoline flowing through a nozzle into an automobile fuel tank at a flow rate of ten gallons per minute is equivalent to over 20 Megawatts (MW). This recharge rate is equivalent to a substantial portion of the total output of a small electric power plant if delivered as electric power. For battery exchange, a $1000 \mathrm{~kg}, 48 \mathrm{kWh}$ lead-acid battery package for a medium size electric bus, if exchanged in one minute, is equivalent to an energy transfer rate of approximately $2.9 \mathrm{MW}$. When the aforementioned energy efficiency factors are included, the usable energy transfer rates for gasoline and leadacid RBI become approximately $2.5 \mathrm{MW}$ and $2.6 \mathrm{MW}$ respectively, nearly the same.

In the 1980 book Electric Automobiles [Hamilton80.2] after discussing the problems associated with rapidly recharging $E V$ batteries, William Hamilton addressed the possibility of battery exchange:

"A final possibility is the battery exchange at a battery service station. With proper design, a propulsion battery can be removed from a car and replaced with another in two or three minutes. The effect is to make refueling as quick and easy as for conventional automobiles. If battery exchange stations were as common as gasoline 
stations, the range limitations of electric cars could become inconsequential.

"Costs of battery exchange, however, seem likely to be greater than for home recharge of a battery kept permanently in the car. The battery exchange stations require facilities, personnel, and an inventory of spare batteries which are unnecessary with home recharging. The costs of an exchange are not likely to be less than for filling up with gasoline, and leasing of batteries to users, with the attendant overhead, is essential. ... A British study estimated that the total cost of battery exchange would be twice that of petroleum (excluding taxes) for a given driving distance." The referenced British report [Weeks78] could not be obtained, but based upon Hamilton's description, the economic assessment appeared to based upon manual handling of lead-acid batteries.

A paper presented at the 1983 EVC Expo in Detroit titled "Refueling of Urban Electric Vehicles" [Gambirasio83] discussed the battery exchange option in considerable detail, and assumed that the exchange process would required at least some "skilled labor". The authors envisioned public battery exchange stations, and discussed the issue of battery rental vs battery ownership. They concluded that battery exchange was an inferior solution for private commuter vehicles with range requirements under 50 miles, but was the superior option in all other situations.

Michael Brown of Electro Automotive Co., Felton, California, has recognized the viability of battery interchange in several seminars he has presented [Brown90].

If primary (non-rechargeable) batteries are used, battery exchange may be the only option. Batteries in this class include metal-air cells, dry-cell chemistries such as carbon zinc, and some alkaline chemistries. Although metal-air batteries (zinc-air, iron-air, aluminum-air) are capable of limited recharging, say for regenerative braking, they are better configured as primary batteries which are "mechanically recharged" by replacement of the metallic electrodes and electrolyte. While the replacement of active battery materials in-vehicle is possible, the process is typically time-consuming and possibly dangerous, often involving the handling of hazardous materials. Off-vehicle replacement is usually required, with automation desirable. Aluminum-air primary batteries have demonstrated exceptionally high specific energy (greater than $300 \mathrm{Wh} / \mathrm{kg}$ ) and power (150-200 W/kg), and favorable economics [Cooper81]. Zinc-air batteries have demonstrated similar performance $(440 \mathrm{Wh} / \mathrm{kg}, 100 \mathrm{~W} / \mathrm{kg})$ and economics [MATSI92], although longevity and reliability constraints remain [Ziganti92].

Battery exchange for electric forklift trucks is already a mature technology. Battery-electric forklift trucks are commonly used for indoor warehouse operations. The weight of a large lead-acid battery pack is of no concern, since the battery simply replaces part of the counterweight on the truck. Forklifts are typically kept in service almost continuously for up to twelve hours. In this service, a battery pack usually lasts approximately four hours. The battery pack is exchanged one or more times a day with a freshly charged one. Typically, three batteries complement each vehicle, with two batteries kept on chargers while one is in service. Battery changing and charging procedures are well regulated under OSHA Regulations 1910.178 and 1926.403. One prominent supplier of semi-automated battery exchange equipment for forklifts is Materials Transportation Company [MTC92].

Battery exchange to extend the in-service period of transit buses has been considered for some time, and has motivated a number of novel battery interchange solutions. During the period from 1974 through 1981, twenty type SL-E M.A.N. transit buses were converted to battery-electric operation by Gesellschaft fur elektrischen Strassenverkehr (GES) using Bosch and Siemans propulsion components and Varta batteries. These were placed in test service in various cities in West Germany. The battery package for this bus was towed on a trailer behind the bus, and replaced by exchange of the battery unit from the trailer using special equipment [Dietrich81]. Each charged battery unit provided a range of $40 \mathrm{~km}$ at an average speed of $20 \mathrm{~km} / \mathrm{hr}$. Several battery exchanges were necessary during each complete 14 hour service shift, with each exchange reported to take 5 to 8 minutes to complete. It was reported that the 20 test buses were operated successfully a total distance greater than 4.5 million $\mathrm{km}$ during the eight year period.

One hundred thirty Mercedes LE-306 and Volkswagen Type II delivery vans were also converted by GES and tested during 1974-81. The Mercedes vans were equipped for battery replacement via a slide-out tray in the underside midsection, although the battery was not usually exchanged in daily service due to the more modest range requirements. In the mid-70's in England, an electric transit bus was constructed by Ribble Motor Services, funded by the British Dept. of Transportation. It was operated in daily transit service in the city of Runcorn. It carried batteries on a trailer which could be detached and replaced to extend the service range. [Collie79.4]

In Japan, a number of battery-electric transit buses have been constructed and tested which have incorporated some means for battery replacement. Mitsubishi, Hino, and Isuzu have all developed transit buses which operate with automatic battery exchange equipment. Four Mitsubishi ME460 buses were operated in Kobe, Japan along five transit routes, accumulating 322,000 $\mathrm{km}$ total mileage between 1975 and 1979. In Kyoto, another Mitsubishi bus services a $23-\mathrm{km}$ route, exchanging batteries several times daily to cover the service day. The Hino BT 900 and Isuzu EV 05 were been deployed in similar service in Nagoya and Osakarespectively [Collie79.3].

In the USA, an experimental "Battronic" bus was constructed and tested by the Boyertown Auto Body Works in the mid-1970's. It used a side-loading scheme to facilitate more rapid manual removal and replacement of the battery packages [Hafer73].

Historically, provisions for convenient battery replacement in passenger-class EVs appears to have been motivated more by the need to service the batteries, than as a means for extension of the useful vehicle range. Lead-acid and similar wet cell technologies require periodic service. The experimental requirements of many of the advanced battery technologies have also prompted consideration of convenient battery removal and replacement in demonstration vehicles. 
At least some consideration is usually given by the vehicle designer to battery access for service or replacement. Some of the means implemented might be considered sufficiently convenient to permit the exchange of the battery package for range extension. Battery installations in trays, which are removable with various degrees of effort, are common. For example, the prototype nickel-iron battery module installed by Westinghouse in the trunk of a small car in 1978-79 was easily replaceable using a specially built cart [Collie79.1]. The previously mentioned VW Type II "Electrotransporters" tested in West Germany by GES also used the replacement cart approach, with the battery package replaceable as a unit from the side of the vehicle. The placement of batteries inside an axial central tunnel has been adopted in several passenger EV designs. This facilitates extraction of the battery package from either the bottom or one end of the vehicle. Bottom extraction from a central tunnel was employed in the CDA Town Car (1976) [Collie79.2], the General Motors Impact EV (1991) and the GM HX3 hybrid [Wyczalek92]. Front replacement of batteries from a structural tunnel was demonstrated in the ESB Sundancer (1970). After removal of the body shell, the batteries could be inserted or removed from the central tunnel of this vehicle using a roll-out tray [Hamilton80.3].

In an ERDA-funded computer analysis of foreign traction batteries for EVs done in the late 1970's, a simulated "standard" EV was described with the facility to quickly extract the battery package from the rear of the vehicle [Collie79.5]. The 1980 Conceptor/General Motors GVan and vehicles of similar configuration used a battery tray located underneath the midsection of the vehicles, removable with specialized equipment [Crocker92].

In the Annual Solar/Electric 500 sponsored by Arizona Public Service Company in March-April each year from 1990 through the present (now operated by Electric Vehicle Technology Competitions, Inc.), many of the competition vehicles have provision for rapid manual battery exchange. In races prior to 1997, an unlimitedclasss one-hour race event virtually required the exchange of batteries by pit crews [APS92]. For example, the winner of the 1991 and 1993 one-hour events was a custom-built competition car sponsored by Trojan Batteries and driven by Eli Schless. This vehicle carried only a small complement of lead-acid batteries, which were swapped manually five times during the race. The lower battery weight reduced the vehicle weight, which was a primary factor in the competitive edge of the car. The batteries were loaded in quickrelease side trays on the car, and were manually exchanged. The exchange process was completed during the race in as little as 18 seconds by a pit crew of four. Several other novel manual battery exchange methods appeared in these races, including dropping the battery pack from the bottom of the vehicle, and insertion of the battery into the side of a vehicle, pushing the exhausted battery out the otherside [Rahders92].

In 1992, Delco Remy battery division consigned the conversion of three GM/Suzuki Geo Metro compact automobiles to electric propulsion, incorporating selfcontained capability to load and unload a battery tray from the bottom of the vehicle [Schless 92, Dunning 93].

Electric vehicles have inspired invention and patent applications for over 100 years. In the field of vehicular battery exchange, inventors have been active since approximately 1970, with several US patents related to
EV battery exchange on file. A US patent was issued in 1973 to Paul Hafer covering a means for loading batteries into the sides of an electrically powered vehicle via a slide-out tray arrangement, much like a desk drawer [Hafer73]. A 1974 patent was issued to Friedhelm Kappei (FRG), which described a battery box with rollers on its underside, which engaged rails in a side cavity of an electric vehicle to facilitate more expedient battery replacement [Kappei74]. In 1981, a US patent was issued to Rainer Klink (FRG) and assigned to Daimler Benz AG, which described a racklike device for insertion and removal of a battery package, which also considered the electrical connections [Klink81].

A U.S. patent was issued to Dale Hane in 1982 which describes an apparatus for inserting and removing batteries from the sides of an electric vehicle, with the old battery removed first, the new battery advanced into position and inserted in its place [Hane82]. A patent was issued in 1984 to Marion Gwyn covering an elevator-like stacking system for storing, inserting and replacing a battery into one end of an electric vehicle. The application claims that using this system, a battery could be replaced in a vehicle in "about one minute" [Gwyn84].

U.S. Patent 5,091,687, filed Jul. 11, 1990, describes an "Apparatus for Exchanging and Charging of Energy Storages of Transport Vehicles." The design uses a circular magazine to exchange and charge energy storage devices of transport vehicles. Patent 5,215,156, filed Oct. 24, 1991, involves an "Electric Vehicle with Downhill Electro-Generating System," a regenerative braking system for electric powered vehicles. Patent 5,225,760, filed Nov. 18, 1991 involves a "Rechargeable Power Pack" holding several batteries. Patent 5,280,223, filed Mar. 31, 1992, involves a "Control System for an Electrically Propelled Traction Vehicle." The design apportions power delivery to individual motors driving separate wheels of an electric powered vehicle in much the same way that a differential apportions power to the driven wheels in an internal combustion powered vehicle. Patent 5,256,954 filed Jul. 9, 1992, involves a "Battery Pack Charging Device." Patent 5,367,242, filed Sept. 18, 1992, involves a "System for Charging a Rechargeable Battery of a Portable Unit in a Rack." Patent 5,224,563, filed Oct. 27, 1992, involves an "Energy Regenerative Mechanism of an Automobile," a regenerative braking system for electric powered automobiles. Patent 5,392,873, filed Jan. 21, 1993, involves a "Structure for Securing Batteries Used In an Electric Vehicle," although the intent is permanent emplacement rather than exchange. Patent 5,343,137, filed Jan. 27, 1993 involves an "Apparatus to Prevent Complete Battery Discharge," which could provide a "limp home" mode at reduced power for electric powered vehicles. Patent 5,373,910, filed Apr. 8, 1993, provides a "Method of Operation for an Electric Vehicle Having Multiple Replacement Batteries." The theory of this design is to draw down one battery of a multiple set, switch to a second battery, and replace the first (discharged) battery with a fresh battery to permit continuous use of the vehicle. Patent $5,394,074$, filed Feb. 22, 1994, involves a "Continuous Cell Charger" that uses a first-in, first-out queue concept for charging multiple batteries at the same time. This technique could be used for EV battery exchange, but is conceived on a much smaller scale for D-cell and smaller dry cell batteries. A U.S. patent was issued in 1994 to Lester Swanson for battery exchange method involving the removal of a battery package from the front 
of a vehicle via a hoisting mechanism. The method seems to pertain only to cases in which the battery package is located under the hood of the vehicle.

In February 1993, it was reported in the Green Car Journal that a British patent was issued in 1992 to N. J. Kruschandl for a quick release battery loading/unloading mechanism which used standardized battery power pack(s) coupled with an in-vehicle energy management instrument and information exchange system [Green93].

Aware of schemes actually employed for battery exchange as early as the late 1800 's and early 1900 's, it is our opinion that many of the recent battery exchange patents would not be defensible in an infringement lawsuit, due to common knowledge prior art, for which U.S. patents were apparently not filed.

\section{BATTERY INTERCHANGE CONFIGURATIONS}

Rapid battery interchange (RBI) generally requires the mechanization of the following functions:

Positioning of the vehicle relative to the exchange apparatus, or positioning of apparatus relative to the vehicle.

- Electrical disconnection of discharged battery.

- Disengagement of battery from vehicle receptacle.

- Physical removal of battery.

- Transfer out of the way of insertion path of replacement battery, into storage/charging queue. Alternatively, vehicle may be repositioned for insertion of battery.

- Dequeuing replacement battery.

- Insertion of replacement battery into vehicle receptacle.

- Physical engagement and securing of replacement battery in receptacle.

- Electrical connection of replacement battery in vehicle.

- Repositioning or securing of exchange apparatus to permit departure of vehicle.

Many implementation means are possible, each imposing unique restrictions on the vehicle design and requiring specialized off-vehicle equipment. Most configurations which have actually been mechanized to date have required some degree of manual assistance by one or more skilled operators. Some are amenable to fully automated transfer, which could potentially facilitate rapid and/or convenient RBI. We focus on candidates amenable to full automation in our discussion below. The discussion is not presumed to be exhaustive, and new innovations are always possible. Figure 3a-f depicts each of the six basic replacement configurations.

a. Exchange from bottom of vehicle. A rectangular, lowheight battery module is suspended from the bottom of the vehicle. This method of battery support and replacement was used as early as 1896 for New York Taxi service, and 1898 for hacks in Paris, as discussed previously. Bottom battery placement is used on many commercial EVs, such as the G-Van, since it minimally intrudes on the interior passenger or payload space. Exchange is accomplished by vertical removal of the exhausted battery package from the bottom of the vehicle. The package is then withdrawn from under the vehicle, or the vehicle is manually pushed forward to alignment with a replacement battery package, which is then inserted underneath the vehicle. Alignment of the vehicle with the exchange equipment is critical, and accommodation of variable vehicle height, with and without the battery payload, have presented significant design challenges.

The Geo metro conversions done in 1992 by Eli Schless for GM Delco Remy (described previously) employed manual battery replacement based on this approach. Several competition vehicles and the 1991-95 Arizona Solar and Electric 500 have used this approach to facilitate the exchange of batteries for range extension. Although not implemented, the GM Impact and previously mentioned G-Van are potential candidates for the exchange method, since the battery package is removed and replaced for servicing from the underside of the vehicle.

A fully automated version of this method involves provision for correction of misalignment of the exchange equipment with the battery receptacle on the vehicle, a means for disconnecting, releasing and lowering the discharged battery and transferring it to the side, and the lifting, securing and reconnection of a new battery into the receptacle. Electrical connection of the pack, and possibly the connection of individual batteries within the pack, are logically facilitated by top-mounted contacts.

This exchange approach is potentially applicable to a wide range of vehicles, including automobiles, light trucks and transit buses. One noteworthy limitation is the height of most traction batteries. The height of the batteries, plus the clearance to the vehicle floor, is subtracted from the interior cabin height. This is a possible imposition in a small car or a low-floor bus, but less of a consideration in vehicles with high floor pans such and trucks and most transit buses.

b. Rear or front battery exchange. The battery package is removed and replaced from the rear or front of the vehicle. Several configurations could be envisioned. A specially configured lift truck may be used to accomplish this manually. A fully automated approach might involve backing the vehicle up to an automated exchange system, that removes and replaces the battery module. The previously described 1984 patent by Gwyn (rear exchange) and 1994 patent by Swanson (front exchange) suggested means for the extraction and queuing of batteries using this approach.

The location of the entire battery complement in the rear or front of a vehicle makes it geometrically compatible with passenger automobile floor plans, and works for many transit bus floor plans also. But unless battery modules are stored at both the front and rear of the vehicle, the weight distribution would seriously degrade vehicle handling and safety. However, the necessity of exchange from both the front and rear would probably make the exchange process too cumbersome and time consuming to be practical.

c. Replaceable battery trailer. The vehicle batteries are stored entirely in a trailer which is towed behind the EV. 
Exchange is accomplished by replacement of the trailer. This method is most practical for transit buses, especially those that are converted from ICE propulsion since this approach minimizes vehicle modifications. For automobiles and light trucks, the method is probably too inconvenient to be acceptable.

Due to the difficulty of exchanging a trailer without some human intervention, a fully automated exchange system based on this method is unlikely. However, variation of this method have been used successfully, such as the previously discussed fleet of twenty M.A.N. SL-E Elektro-Buses in Dusseldorf, FRG. In this case, the trailer remained attached, but the batteries were exchanged from the trailer, which was designed specifically for this purpose. The exchange process was almost fully automated, once the trailer was manually aligned with the exchange apparatus [Collie79.3].

d. Side pocket battery exchange. Batteries are located in panners or pockets in the side of the vehicle. This placement is preferred for low-floor transit buses, since it creates a minimum intrusion on the useful interior passenger space. The central battery placement also yields a favorable vehicle weight distribution.

Manual exchange from the pockets may be done using a forklift truck or palette trolley to transfer the batteries. This approach was described in the previously discussed 1973 U.S. patent by Hafer, described in the Background section. The concept appears to have been first employed in an experimental version of the popular Battronic delivery van in 1974, but earlier examples in Japan or Europe are quite possible. Several current electric bus vendors have incorporated provisions for this exchange method, including Specialty Vehicle Manufacturing Corp. in Los Angeles, CA [Auchard93], Bus Manufacturing Corporation in Santa Barbara, CA [EVM92], U.S. Electricar in Redwood City, CA, and School Buses built by Bluebird and Thomas Built. It is probably not an acceptable method for passenger automobiles, due to the interior intrusion of the side areas occupied by the batteries.

While this configuration is amenable to manual battery exchange, fully automated exchange from side pockets is challenging due to the number of different motions needed to remove and replace each battery, and the critical alignment requirements. A fully automated approach might involve the vehicle driving between the exchange units on either side, with additional provision for automatic alignment.

e. Lateral pass-through RBI. The charged battery module is inserted into one side of the vehicle, which pushes the exhausted battery module out the opposite side. This configuration was described in U.S. patents by Hane (1982) and others. A lateral embodiment of this technique was used by a converted Volkswagen Rabbit competition vehicle in the 1991-95 APS Solar and Electric 500 races. This method generally imposes the most severe restrictions on the vehicle design, since both insertion and removal apertures must be provided. Interference with vehicle drivetrain components or structural frame members of existing vehicles probably preclude most conversion, and suggest the ground-up construction of a vehicle to incorporate this technique. The pass-through feature is fundamental to the high speed transfer, since the insertion and removal operation are accomplished concurrently.

If the vehicle is stationary, the exchange equipment must straddle both sides of the vehicle, facilitating insertion from one side of the vehicle and removal on the other. The vehicle drives between the units and stops in correct alignment with the exchange units. Lateral, longitudinal and vertical vehicle alignments with the exchange units are critical.

f. Longitudinal pass-though RBI. Alternatively, in an axial embodiment of the pass-through technique, batteries pass through the vehicle along the axis of travel. Practicality dictates that both batteries remain stationary while the vehicle itself is rolled (unpowered) forward or backwards, repositioning it above the new battery. Batteries are located in a central longitudinal tunnel, open at both ends of the vehicle. While battery placement in a central tunnel has been common in EVs as early as the 1970 ESA Sundancer, and possibly earlier, removal and replacement of the battery package has typically been via one end or the bottom of the vehicle, with various degrees of difficulty.

As with lateral exchange, a key limitation of this approach is the required full-length unobstructed battery tunnel or channel, which precludes a conventional rear axle or central placement of the motor or transmission. One workable solution is separate motors and gear reductions for each driven wheel. While more costly, this is not necessarily bad since dual motors eliminates the need for a differential. The central tunnel imposes some design restriction also. In a passenger car, the tunnel width may intrude upon available seating area. For low-floor transit buses, the longitudinal tunnel could pose a prohibitive design restriction.

A fully automated mechanization of this method may have the vehicle engaged and aligned by a track arrangement and towed through the mechanism, much like a car wash. Theoretically, the battery exchange could be accomplished without the vehicle actually stopping, but at very low speed. 


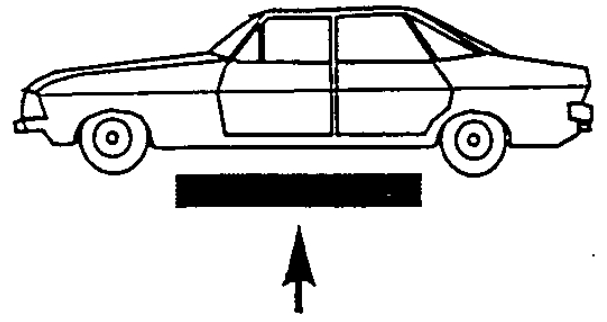

a. Bottom Battery Exchange.

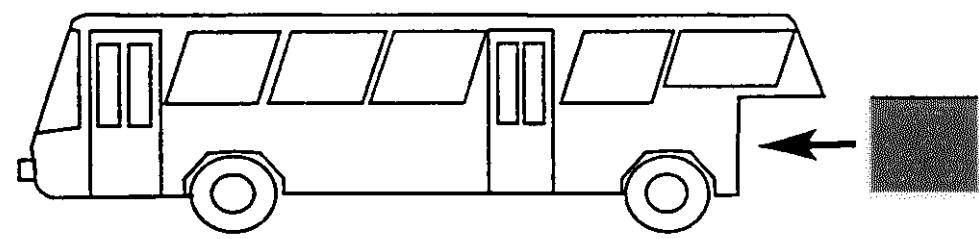

b. Rear Battery Exchange.

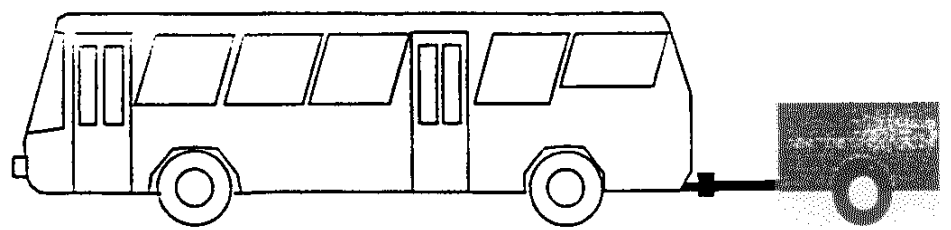

c. Replaceable Battery Trailer

c. Replaceable Battery Trailer.

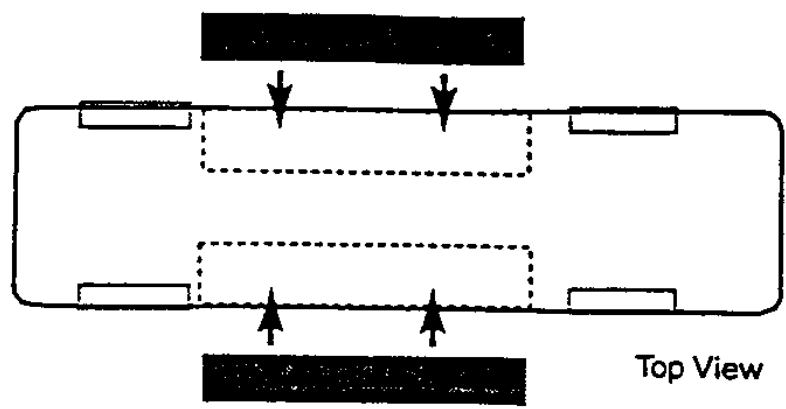

d. Side Pocket Battery Exchange.

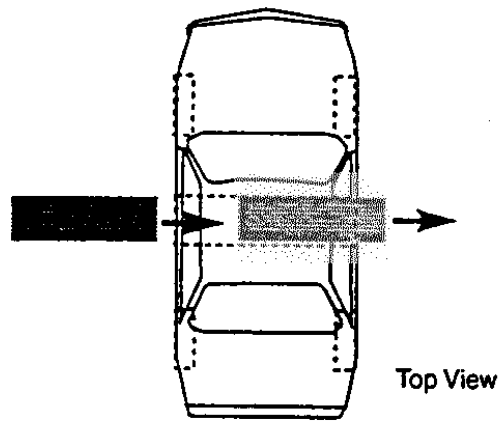

e. Lateral pass-through.

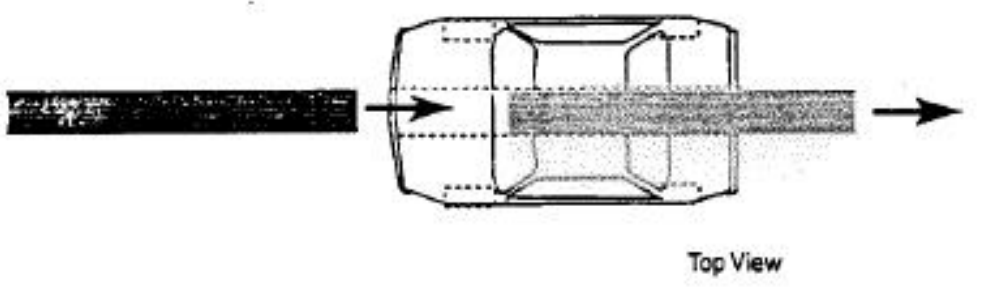

f. Longitudinal pass-through.

Figure 3. Automated Battery Exchange Configurations.

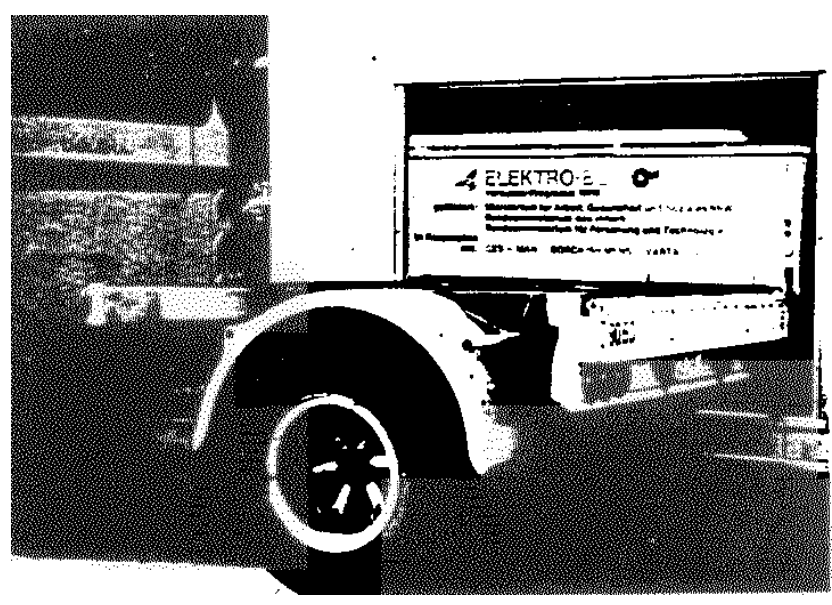

Figure 4. M.A.N. Battery Exchange Trailer, from [Collie79.3]. 


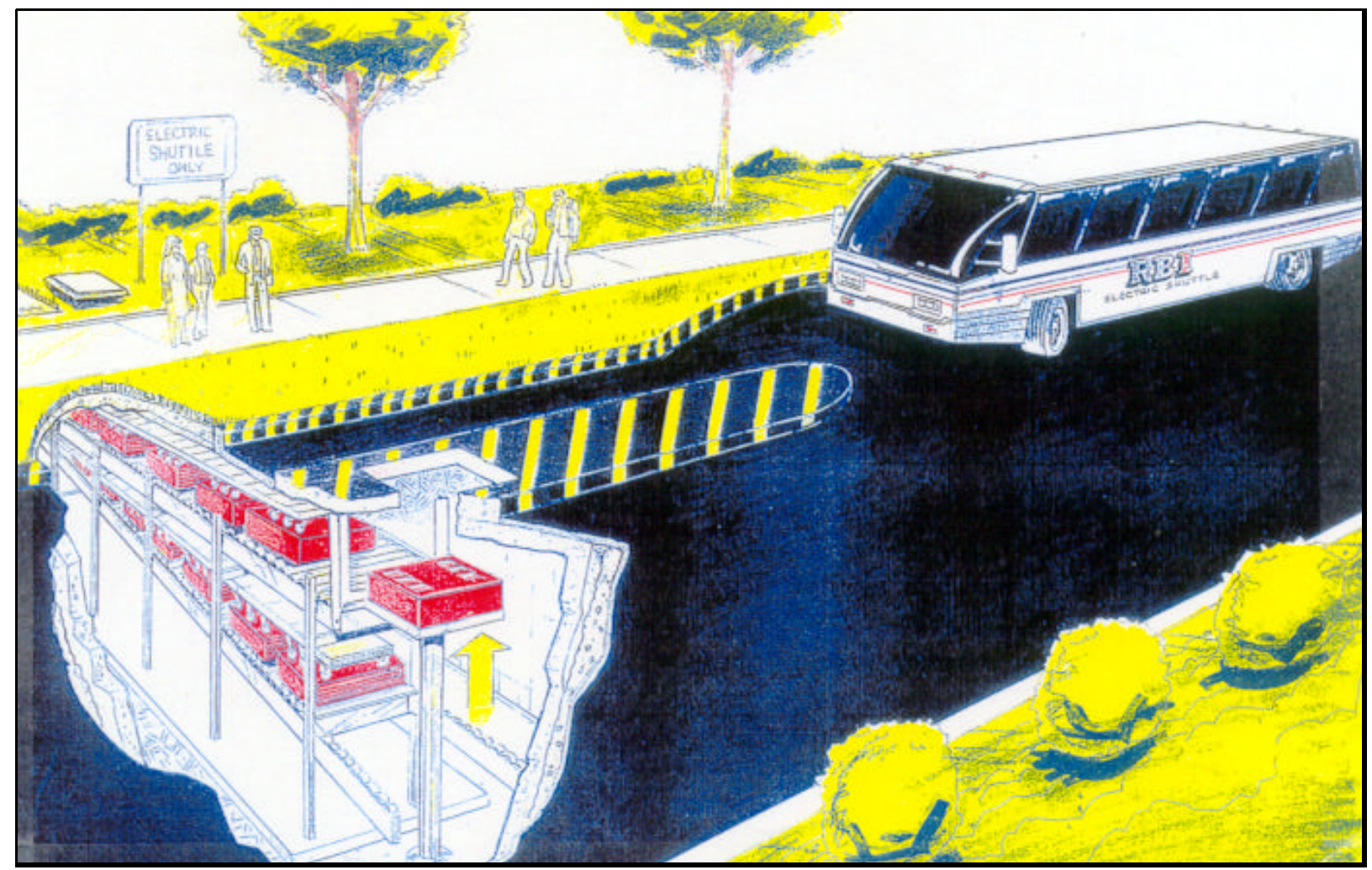

Figure 5. Design Study for RBI Electric Bus, Cal Poly, San Luis Obispo, 1991 [MacCarley94].

\section{SAFETY AND REGULATORY CONSIDERATIONS FOR EXCHANGEABLE BATTERY ELECTRIC VEHICLES}

\begin{abstract}
Vehicles sold in the USA for operation on public highways, regardless of propulsion source, are subject to Federal Motor Vehicle Safety Standards (FMVSS), published by the National Highway Traffic Safety Admistration (NHTSA) ${ }^{\text {}}$. Electric vehicles generally pose somewhat different hazards to both the vehicle operator, other vehicles and pedestrians than ICE vehicles. Provisions for the rapid exchange of the vehicle battery introduce additional safety concerns associated with both the vehicle and the battery exchange equipment.
\end{abstract}

The large mass of batteries usually make EVs heavier than ICE vehicles, degrading both acceleration and braking rates. Rupture of a battery case could result in a spill of dangerous reactants, and possibly a hazardous waste spill incident.

One example of the peculiar hazards associated with batteries occurred in the Second Annual Solar and Electric 500, April 26, 1992 in Phoenix. The race leader, a Solectria car powered by zinc-bromide batteries, lost coolant and leaked bromine gas, sending the driver and fourteen officials and race team members to the hospital [AP92].

EV Battery voltages can range from 48 to over 400 volts. Available current up to 1000 amps (or more for larger

\footnotetext{
${ }^{1}$ Current FMVSS passenger car standards can be obtained via the Internet at www.nhtsa.dot.gov/search97cgi/s97_cgi.exe
}

vehicles) makes possible tremendous energy release in the event of a short circuit. Design for prevention of electrical faults and battery puncture are particularly important for battery exchange, especially if the operation is performed quickly by an automated apparatus.

\section{RBI SAFETY CONCERNS PERTINENT TO THE VEHICLE}

Accidental release of the battery module in the event of a collision. If the battery can be exchanged quickly, it is likely to be less securely mounted than a permanent battery installation. Accidental release of a battery module weighing 400 to $500 \mathrm{~kg}$ could increase the level of damage and hazard in a collision, especially to the other vehicle.

Battery protection from the elements, and integrity in the event of collision or rollover is also a greater concern with an RBI vehicle, since the battery would probably be more exposed than in a fixed battery installation.

Ventilation of released gases would probably be a reduced concern with RBI, but accumulation of road debris, mud, water and snow pose an additional problem, especially in the area of the electrical contacts. Rain or slush laden with road salt is an effective conductor, capable of shorting and/or degrading battery and instrumentation contacts.

Electrical connectors that must engage automatically and quickly in an $\mathrm{RBI}$ vehicle are likely to be more susceptible to poor contact or accidental short due to misalignment or mishandling. The contactor system must be completely "idiot-proof," capable of withstanding backward insertion of the battery module, poor vehicle alignment, and possibly excessive vehicle speed upon docking with the battery exchange equipment. 
Provision for fail-safe docking with the automated battery exchange equipment is a nontrivial concern. Depending on the interchange scheme employed, the level and attitude of the vehicle may be critical.

Standardized interfaces must be developed to accommodate electrical connections to instrumentation, auxiliary batteries, and possibly to battery environment control systems (e.g., for high-temperature batteries or external reactant reservoirs). Each additional system increases safety and reliability concerns to some degree.

\section{SAFETY CONCERNS PERTINENT TO THE BATTERY EXCHANGE EQUIPMENT}

The battery exchange unit must be easily accessible, but pose no safety hazard to the general public or the EV operators or exchange station maintenance personnel. If accessible to the public, it must be resistant to vandalism and theft.

If a large inventory of batteries is stored, each in various states of recharge, provision must be made for safe dissipation or absorption of the by-products of the charging process, such as hydrogen gas in the case of lead-acid or nickel-iron batteries. The possibility of an explosion hazard exists, which may be a necessary consideration in the location and housing of the exchange equipment.

The concurrent recharging of many batteries at the exchange site could draw significant electric power from the utility grid, necessitating large power handling and distribution equipment. Hazard levels are increased accordingly.

The battery exchange equipment must be designed to overcome the various docking problems described previously, with immunity to damage to itself, or hazard to the driver or public.

The means for automated monitoring or accounting for the battery exchange must be both secure and safe. While not directly a safety issue, security and safety concerns are usually closely linked.

\section{BATTERTY EXCHANGE-RELATED PROVISIONS OF FMVSS}

While electric conversions of existing ICE vehicles often rely (questionably) upon the original vehicle certification prior to conversion, or are granted exemptions based upon limited production, purpose-built EVs generally comply with current FMVSS passenger car or truck safety standards. Among the first vehicles certified under these standards were the GM/Conceptor G-Van conversion (1989), the Nissan FEV [Wyczalek92] and the Chrysler T-Van [Mader91]. FMVSS regulations specific to EVs are still in the formative stages. An Advanced Notice of Proposed Rule Making (ANPRM) was originally published in the Federal Register in December 1991 published. (49 CFR Part 571 Docket No. 91-49; Notice 2). In October 1992, the Electric Vehicle Association of the Americas released an executive summary pertaining to FMVSS for EVs [Risser92.2]. In December 1992, based upon public and industry comments, the NHTSA concluded that it would be premature at this time to initiate major rulemaking in this area, and initiated the ongoing fact-finding research program B.02.02.08 "Electric Vehicle Safety" to identify problems electric vehicles may encounter in complying with existing crashworthiness standards and determine potentially unique electric vehicle safety hazards that may require implementation of new standards. This research and testing program remains in progress as of December 1998. A special policy exemption was approved for very slow (under $25 \mathrm{mph}$ ) vehicles, particularly electric golf cars, in 1998 under 49 CFR Part 571. (This class of vehicles is a good candidate for RBI.)

Battery charging standards have proceeded ahead of other EV-specific standards, driven by the proliferation of incompatible proprietary charging systems. Charging facilities will eventually be required to comply with applicable provisions of Article 625 of the National Electric Code, SAE recommended practice for inductive EV couplers (SAE J1773), and/or SAE proposed recommended practice for conductive EV couplers (SAE J1772, working draft). These standards are of direct relevance to automated multi-battery charging systems.

For passenger cars, the NHTSA has proposed minor amendments to four existing standards to explicitly address EVs: 1) controls and displays, 2) windshield defrosting and defogging systems, 3) passenger car brake systems, and 4) hydraulic brake systems. Specific provisions of the current FMVSS which are relevant to vehicular battery exchange are discussed below.

\section{Occupant/Driver Collision Protection}

General vehicle occupant safety concerns are dealt with in the following standards: FMVSS 571.201, 571.203, 571.208, FMVSS 571.208 (Occupant crash protection), FMVSS 571.209 \& 571.210 (Seat belt issues), FMVSS 571.214 (Side impact), and FMVSS 571.216 (Roof crush/roll issues). All of these standards directly apply to EVs but do not specifically address safety problems that electric propulsion systems might pose during an impact or collision. Three major areas of specific concern are 1) potential for shock hazard, 2) occupant or bystander contact with electrolytes or reactants, and 3) battery system explosion. All three of these concerns are exacerbated to some degree in RBI vehicles, due to the possible tendency towards greater exposure and weaker mounting of the battery package in the vehicle. In addition, any meters or gauges on the instrument panel in an EV would need to present minimal or no potential for shock hazard in the event of an accident. This would apply to any additional instrumentation added to facilitate RBI.

\section{Low Speed Front and Rear Collisions}

Safety considerations for low speed front and rear collisions are covered in FMVSS 581, which deals primarily with bumper standards. Depending on the vehicle class, the front and rear bumpers may be required to withstand collisions with a stationary object at several specific speeds with no damage to critical vehicle systems. Cited critical systems include the braking, propulsion, suspension, and steering systems as well as hood, trunk and doors. In essence, the functionality of the car would need to remain unchanged. For an EV, all battery mounting systems and connectors should remain undamaged in low velocity collisions. An $\mathrm{RBI}$ configuration which loads the battery from the front or rear of the vehicle would be particularly at risk in a front or rear impact, since the means by which the 
battery is held in place could possibly be either compromised or the battery itself could be ejected.

The large mass of the battery pack poses unique concerns in multi-vehicle crashes. While electric vehicle crashes have been few and little post-accident analysis data exists. Damage analysis following a $30 \mathrm{MPH}$ barrier crash test of the GM/Conceptor G-Van identified a significant risk of ejection of the bottom-mounted 1200 $\mathrm{kg}$ battery pack [Palvoelgyi90]. In the case of battery mounts designed for RBI, the mountings would need to withstand not only large shocks due to major collisions, but also the cumulative effect of repeated smaller shocks over an extended period of time. Regardless of specific battery internal design and construction, its storage ability and functionality should remain unchanged after impact. The electric storage and propulsion systems should not experience any degradation in performance immediately after a low-speed crash impact, or after any number of non-destructive impacts. Certification tests include pendulum, barrier, longitudinal impact, and corner impact tests described in FMVSS 581 and SAE J980a.

\section{Side Impact Protection}

Existing regulations regarding this subject are found in FMVSS 571.214. The EV would need to meet these standards, but in addition, no extra danger should be introduced to the driver or occupants or the vehicle due to the nature of the vehicle. Side impact should not expose dangerous electrical wiring or battery electrolytes to driver, passengers or bystanders.

Extrapolating from these provisions, the battery enclosure should be capable of surviving the side impact test without presenting safety hazards to anyone involved in the impact situation. An RBI configuration which loads the battery from the side or bottom of the vehicle would be particularly at risk in a side impact, since the battery could possibly face the full impact of the collision or be completely ejected.

\section{$\underline{\text { Roof Crush and Roll Resistance }}$}

Existing regulations regarding this subject are addressed in FMVSS 571.216. In the event of a roll, vehicle occupants and bystanders would need to be safe from various electric components, and battery electrolytes or reactants. The battery compartments should remain intact, which will guarantee the battery system does not explode, leak electrolytes, or release dangerous fumes.

\section{General Collision Safety Considerations}

In general, the EV should be designed so that the electric propulsion circuit remains electrically insulated from other conductive portions of the vehicle in the event of a collision or other adverse conditions. Also, the vehicle must be able to comply with FMVSS 571.208 and 571.301 , with all battery materials remaining outside of the passenger compartment.

The NHTSA considers a disconnect device vital so that when collisions occur, vehicle occupants, rescue workers, or other persons do not risk electric shock resulting from the propulsion battery circuitry shorting with the vehicle chassis. The presence of an easily exchangeable battery on board the EV could be expected to increase the possibility of loss of electrical isolation, because of electrical contacts that can be rapidly and automatically disconnected.

Safety regulations specific to how the storage cells are secured in the vehicle are anticipated. This is an area of direct concern to RBI EVs, since these regulations must accommodate the many ways that a battery package could be configured for ease of interchange. Storage cells represent the one most concentrated mass on the $\mathrm{EV}$, which renders them most susceptible to the effects of inertial forces during and after impact. Unfortunately, it is not possible for restraints of any type to be able to keep the storage cells secured perfectly in all collision or impact scenarios.

\section{Battery-Specific Safety Issues}

The battery will uniquely require both the need for proper venting as well as prevention of electrolyte spillage in the event of some type of adverse condition. For lead-acid batteries, the battery compartment shall have ventilation which will be adequate to maintain the concentration of hydrogen below $4 \%$ by volume (the minimum flammability concentration) during vehicle operation, charging and maintenance. This is, of course, very specific to the type of storage cell being used, with other specifications necessary for other battery chemistries. Vehicles with vents shall have flame barrier provisions to inhibit battery explosions. The vehicle shall also have a safety device operable from normal operator position to provide positive battery disconnect. This device should operate automatically in adverse conditions such as collisions or rollovers.

FMVSS 571.301 covers fuel system integrity in the event of collision. The obvious tendency here is to treat electrolyte spillage as a type of fuel spillage. This would be of notable concern for RBI. A possible consequence of RBI-capable vehicles would be both lighter and possibly weaker materials used in the particular battery casings, and a tendency toward rough handling during and after the battery interchange.

\section{$\underline{R B I}$ - Specific Component Standards}

EV standard setting activities are in progress, especially with regard to charging connectors and systems. The Society of Automotive Engineers (SAE) and Electric Power Research Institute (EPRI) are lead contributors to these efforts. Provisions for rapid battery interchanging would increase the need for standards, both electrical and mechanical. The primary concern associated with $\mathrm{RBI}$ is that the compromise of the design which enables the battery to be quickly changed inherently requires it to be held less securely in place in the vehicle. This includes both the physical battery restraints and the electrical connections to the battery. Connectors would need to disengage quickly, but would also need to be held securely in place during normal operation of the vehicle. The integrity of the battery mounts and connectors should not degrade in any way over an extended period of time under normal operating conditions.

RBI-related standards could contribute significantly to user acceptance and feasibility, particularly with respect to exchangeable batteries. While not without additional infrastructure considerations, the standardization of the dimensions, voltage, connector configuration, and attachment mechanisms for a series of exchangeable battery packs could theoretically make $\mathrm{RBI}$ accessible 
for non-fleet vehicles. It is doubtful, however, that existing and anticipated EV standards will directly consider RBI, although they will certainly apply to it.

\section{ECONOMIC FACTORS FOR RBI COMPARED WITH CONVENTIONAL EV REFUELING}

An analysis was performed to estimate the relative annual cost of purchase, ownership and operation of various configurations of electric vehicles: conventional fixed-battery (slow-charge-only), fixed battery with fast charge capability (fast-charge), and exchangeable battery (RBI) vehicles. Details of the analysis are contained in [MacCarley94], [Seifoddini94], and [MacCarley95]. Only a summary the assumptions and results is presented here.

Key cost items associated with all EVs include the amortized vehicle capital cost, maintenance and service costs, electric power cost, battery replacement costs over the vehicle life time, and the amortized cost of the support equipment, which could be a slow or fast charger, or a battery exchange unit. The support costs can be shared between multiple vehicles in a fleet, or in general service of many public users at a common location.

An EV with RBI capability would be expected to incur different capitalization and operating costs than an EV with a permanent battery installation. We base the analysis upon combinations of four vehicle mission scenarios, three vehicle types, and four usage patterns. Lead-acid battery technology is assumed in all cases, including slow and fast charge batteries, and for RBI battery modules.

The analysis attempts to reduce to an equivalent annual cost for the vehicle(s), support equipment, electric power costs, replacement batteries, and periodic service. All vehicles and support equipment are assigned a useful life or fifteen years, with zero salvage value. It is assumed that each complete slow-charge cycle to an $80 \%$ depth of charge consumes $0.2 \%$ of the life of the battery. A fast charge cycle to a $40 \%$ charge depth consumes $1.0 \%$ of the battery life. Batteries charged by RBI exchange equipment are slow-charged. Power costs are incurred at either off-peak rates of $\$ 0.06$ per $\mathrm{kWh}$, or $\$ 0.12$ per $\mathrm{kWh}$ for peak power (Schedule E-19 metered time-of-use service). Fast charging is assumed to always occur during peak hours, while slow charging and $\mathrm{RBI}$ module charging is assumed to occur at night, using off-peak power. Fast chargers are assumed to have the capability of also slow-charging a battery.

\section{Vehicle Energizing Classes}

1. Slow-charge, conventional EV.

Vehicles are charged at a six to eight hour rate overnight. Daily range limited to 50 miles assuming at maximum $80 \%$ depth of discharge. Battery life: 500 cycles to $80 \%$ depth discharge.

\section{Fast-charge EV}

Vehicles in this class can be charged at either a slow (68 hour) rate to provide $80 \%$ usable capacity, or fast charged in fifteen minutes to provide $40 \%$ of usable capacity. Fast-charge-capable lead-acid batteries assumed to have same cost as slow-charge batteries.
Peak power used for fast charging, which is assumed to occur during day time hours only as needed to extend the vehicle range beyond 50 miles. Each fast charge adds 25 miles to the vehicle range. For privately owned EVs in this class, owner has a slow charger at home, and the option to use a public or institutional fast-charge service station. For fleets, all vehicles are slow charged at night, but have the option to fast charge during the day if range requirements dictate. Separate slowchargers are provided for each vehicle in fleet, while a single fast-charger services all vehicles in the fleet.

\section{RBI EV}

Vehicles refueled by battery exchange. Exchanged battery modules are slow-charged by exchange equipment using off-peak power. Each module provides a maximum range of 50 miles per exchange, assuming $80 \%$ charge depletion.

\section{Usage Schedules}

\section{Commuter}

50 miles per day, 5 days per week, 50 weeks per year. Total of 12,500 miles per year. For commuters, this represents travel to and from a place of employment which is 25 miles away, in mixed driving. All vehicles slow charge only. No battery exchange required beyond once a day. No fast charging required.

\section{Fleet Service}

100 miles per day, 5 days per week, 50 weeks per year. Total of 25,000 miles per year. This represents 100 mile per day fleet service. Slow-charge-only EVs cannot meet this range requirement.

\section{Transit Service}

150 miles per day, 5 days per week, 50 weeks per year. Total of 37,500 miles per year. The represents 150 mile per day fleet or public transit service. Slow-charge-only EVs cannot meet this range requirement.

\section{General Automobile}

50 miles per day 4 days per week, plus 100 miles per day 1 day per week, plus 300 miles per day, 4 days per year. Total of 16,200 miles per year. This scenario attempts to model heavy consumer use of a generalpurpose family car. The car is used for commuting to and from employment 25 miles away 5 days per week. One day each week, the owner needs an additional 50 miles of range to complete errands during the daytime. The car is used to take two extended trips each year to locations three hundred miles away. Travel to and from the location is completed in one day, each way. Public battery exchange or fast charge stations are assumed to be conveniently located as required to provide range extension beyond 50 miles per day. A slow-charge-only EV cannot meet these use requirements.

\section{Vehicle Mission Scenarios}

1. One electric automobile or light truck with dedicated support equipment.

This scenario involves a single electric automobile or light truck serviced by single battery charger (slow or fast) or exchange system, used exclusively to support this vehicle. This scenario approximates a single vehicle in private, commercial or public transit service. Examples of this might be a single privately owned EV for commuter use, or an institutionally owned single EV used for parking enforcement, delivery, or taxi/shuttle 
service. Daily range requirements greater than 50 miles preclude slow-charge conventional EVs.

The entire cost of the support equipment (charger or exchanger) is included in the cost analysis for the single vehicle. For a conventional (slow charge) EV, this scenario includes the cost of a single battery charger capable of fully charging the vehicle batteries in six to eight hours. For a fast-charge $\mathrm{EV}$, the cost of a single high-rate charger is included, capable of charging the vehicle batteries to $40 \%$ capacity in under fifteen minutes, and also capable of slow (6-8 hour) charge rates. For an $\mathrm{RBI}$ vehicle, the cost of the exchange equipment and extra exchange battery modules are included as required to meet range requirements. Also, it is assumed that the RBI vehicle always fuels by battery exchange, even though the battery could be charged in the vehicle.

This scenario is somewhat unrealistic for fast-charge or $\mathrm{RBI}$ vehicles since the fast-charger or exchanger supports only a single vehicle. The cost of the fastcharger or exchanger, however, is relatively low since it is sized to support only one vehicle.

Off-peak power costs are used for-slow charge EVs. Fast-charge EVs are slow charged at night to provide 50 mile range using off-peak power, but fast charged during the day to provide range requirement beyond 50 mile per day. For RBI EVs, all battery modules assumed to be slow-charged.

2. Twenty vehicle fleet of automobiles or light trucks with common support equipment.

This scenario involves twenty identical EVs serviced by common support equipment. This might represent a commercial fleet, or a company-supported commuter vehicle plan. Commercial or institutional examples of this scenario might be a small fleet of electric vehicles for daily parking enforcement, delivery or utility meter reading. Vehicle batteries are charged or exchanged at a common location.

Range requirements over 50 miles per day preclude slow-charge EVs. For ranges under 50 miles per day, slow-charge EVs are feasible, and overnight off-peak charging is assumed. A separate slow-charger is used for each EV, for a total of twenty chargers. For fastcharge EVs, a single common fast-charger is used, which is expected to service all twenty fleet vehicles. This is overly optimistic unless the fast-charge can be done so rapidly that the maximum vehicle wait time for use of the charger is sufficiently short that the intended service requirements will not be impacted. For twenty vehicles, fast charging for fifteen minutes each plus five minutes for hookup, the fast charger would be tied up for six hours 40 minutes each day.

For $\mathrm{RBI}$ vehicles, this scenario includes a single battery exchange unit that services all vehicles. The exchange equipment is assumed to have the capability to inventory and slow charge twenty batteries simultaneously. The amount of time that any vehicle ties up the exchange equipment is assumed to be sufficiently small such that the service requirements are not limited. If each exchange is completed in five minutes, the exchanger would be tied up one hour and 40 minutes each day. For RBI, extra battery modules are assigned to each vehicle as needed to meet the range requirements.

\section{Fleet of twenty electric public transit vehicles.}

This scenario involves twenty identical electric transit vehicles serviced by common support equipment.
Batteries are charged or exchanged at a common location.

Range requirements over 50 miles per day preclude slow-charge vehicles. For ranges under 50 miles per day, slow-charge only is acceptable, and overnight offpeak charging is assumed. A separate slow-charger is used for each vehicle, for a total of twenty chargers. For fast-charge, a single common charger services all twenty vehicles.

For $\mathrm{RBI}$ vehicles, this scenario includes a single battery exchange unit that services all vehicles. The exchange equipment is assumed to have the capability to inventory and slow charge twenty batteries. For RBI, extra battery modules are assigned to each vehicle as needed to meet daily range requirements.

4. Public Service Station serving 100 private automobiles or light trucks per day.

In this scenario, a mix of different automobiles or light trucks, all compatible with some fast charge or RBI battery standard, are serviced by public service stations, which provide either fast-charge service or RBI service. All vehicles are also slow-charged overnight at home, which requires that all vehicle owners (including $\mathrm{RBI}$ vehicles) have a slow charger at home. The exchange or fast-charge fees charged by the service station include energy costs, the amortized costs of the fastcharge or battery exchange equipment, and the usagebased costs of all inventoried batteries. Fully automated self-service operation is assumed. This represents a possible consumer scenario if either fast charge or RBI standards are established and accepted by the public.

For $\mathrm{RBI}$, one battery exchange unit is operated by the station, which with the capacity to store and charge 50 batteries. Even though the exchange unit serves a 100 user population, only a $20 \%$ average subset of these users need exchange service to extend the range on any given day. For fast-charge EVs, the station operates one fast charger. Even though the fast charger serves a 100 user population, only a $20 \%$ average subset of these users need fast charge service on any given day.

\section{Analysis Results}

Table 1 indicates the annual cost for each of the feasible combinations of the four vehicle missions, four usage schedules and three refueling types. In situations for which the range of a slow-charge-only vehicle is acceptable, it's cost is consistently the lowest. For all vehicle missions and all usage schedules except commuter (for which range extension is not required), the RBI option appeared to be consistently less costly than the rapid recharge option. Dominant factors were amortized battery costs and energy costs.

Table 1. Summary of Comparative Cost Results.

Vehicle Mission: Single Automobile or Light Truck with Dedicated Support Equipment.

\begin{tabular}{|c|c|c|c|}
\hline Usage Schedule & Slow-Charge & Fast-Charge & RBI \\
\hline Commuter & 2,499 & 2,940 & 2989 \\
\hline Fleet & N/A & 13,936 & 4,674 \\
\hline Transit & N/A & 24,931 & 6,359 \\
\hline General Auto & N/A & 6,195 & 3,488 \\
\hline
\end{tabular}


Vehicle Mission: Fleet of 20 Automobiles or Light Trucks with Dedicated Support Equipment.

\begin{tabular}{|c|c|c|c|}
\hline Usage Schedule & Slow-Charge & Fast-Charge & RBI \\
\hline Commuter & 2,499 & 2,502 & 2,455 \\
\hline Fleet & N/A & 13,358 & 3,970 \\
\hline Transit & N/A & 24,213 & 5,485 \\
\hline General Auto & N/A & 5,715 & 2,904 \\
\hline
\end{tabular}

Vehicle Mission: Fleet of 20 Transit Buses with Dedicated Support Equipment.

\begin{tabular}{|c|c|c|c|}
\hline Usage Schedule & Slow-Charge & Fast-Charge & RBI \\
\hline Commuter & 15,216 & 15,710 & 15,962 \\
\hline Fleet & N/A & 50,896 & 23,250 \\
\hline Transit & N/A & 86,082 & 30,537 \\
\hline General Auto & N/A & 26,125 & 18,120 \\
\hline
\end{tabular}

Vehicle Mission: Public Fast-Charge or RBI Station serving 100 Vehicles.

\begin{tabular}{|c|c|c|c|}
\hline Usage Schedule & $\begin{array}{c}\text { Slow-Charge } \\
\text { Only }\end{array}$ & $\begin{array}{c}\text { Slow and Fast- } \\
\text { Charge }\end{array}$ & RBI Only \\
\hline Commuter & 2,499 & 2,549 & 2,598 \\
\hline Fleet & N/A & 13,420 & 4,158 \\
\hline Transit & N/A & 24,290 & 5,718 \\
\hline General Auto & N/A & 5,766 & 3,060 \\
\hline
\end{tabular}

\section{SURVEY OF INDUSTRY AND PUBLIC PERCEPTIONS}

A limited survey was conducted of the EV community to assess the acceptance and possible market feasibility of $\mathrm{RBI}$ for EVs. A summary is presented here. Details are contained in [MacCarley94]. Five target groups were identified for participation in the survey:

\section{Electric Vehicle Manufacturers}

2. Electric Vehicle Battery Manufacturers

3. Manufacturers and Suppliers of other EV Components or Sub-Systems

4. Institutional EV Users

5. Private EV Owners or Potential Owners

For each of these five categories, specialized sets of survey questions were created, which emphasized the expertise and point of view of the target group. Standardized survey data forms were created for all groups. A membership list supplied by the Electric Vehicle Association of America (EVAA) was used as a starting point for identifying potential commercial and institutional respondents. A survey of available popular and technical literature and EV enthusiast groups yielded additional possible participants. A total of 75 possible participants in the six target groups were identified. Of these, 74 completed the survey. Interviews were performed during September and October 1992.

\section{SUMMARY OF SURVEY RESULTS BY TARGET GROUP}

\section{Group 1: Electric Vehicle Manufacturers}

Surveying a total of 32 respondents, this target group was the largest of the survey categories. It included the U.S. Big Three automakers, German, Australian, and Japanese car manufacturers, along with the small companies in the United States who convert ICE cars to electric and those who build electric cars or buses from the ground up.

Of the 32 electric vehicle manufacturers surveyed, 21 felt there was value to building EVs that could rapidly exchange batteries. Five others in the group specified there was value to building only fleet vehicles that could rapidly exchange batteries. 21 respondents felt $\mathrm{RBI}$ would enhance the value of EVs. Fleets and commercial vehicles were the favored classes of vehicles that respondents felt would be the best candidates for RBI.

Many of the surveyed EV manufacturers had never considered provision for battery exchange. Some stated that this was proprietary information. Sixteen respondents indicated an interest in being involved in the design and/or manufacture of $\mathrm{RBI}$ equipment.

There were many different ideas for battery module configurations. Almost all of the 32 respondents felt that quick-change battery modules and vehicle receptacles should be standardized in some way. However, a wide variety of answers were given for the way such standards should be established. All those surveyed said they would conform to standards if established.

\section{Group 2: Battery Manufacturers}

Twelve U.S. and Canadian battery manufacturers or representatives of foreign manufacturers were surveyed in this category. A little over half of the 12 battery manufacturers produce lead-acid batteries. Five produced only advanced technology batteries with intended applications in EVs. Three produced both leadacid and advanced technology EV batteries.

Nine respondents perceived value in batteries that can be rapidly exchanged, and seven of those felt that rapid battery interchange capability would enhance the value of their products. The classes of vehicles that would be the best candidates for RBI using the respondents' batteries were mainly fleets and buses.

Seven battery manufacturers had not considered automated battery exchange, while four had. Six of the twelve respondents said they would have an interest in the design and/or manufacture of $\mathrm{RBI}$ equipment. Ten respondents felt that quick-change battery modules and vehicle receptacles for these should be standardized. Suggested methods for establishing these standards, were varied.

Group 3: Manufacturers and Suppliers of Other EV Components or Subsystems

There were fifteen survey respondents in the category of manufacturers and suppliers of other EV components or subsystems. The manufacturers produce a wide variety of components and subsystems. Nine of the fifteen 
respondents perceived value in building EVs that could rapidly exchange batteries. Eight respondents felt that $\mathrm{RBI}$ would enhance the value of their products. The classes of vehicles which they considered as the best candidates for RBI were bus and commercial fleets, truck and utility fleets. Seven respondents stated 'all vehicles' are the best candidates.

The majority of the respondents had not considered interchangeable battery configurations prior to the survey. Six respondents stated interest in being involved in the design/manufacture of RBI equipment. All fifteen respondents felt that quick-change battery modules and vehicle receptacles for these should be standardized. Thirteen felt that other manufacturers would comply with such standards, if established.

\section{Target Group 4: Institutional EV Users (eg., fleet or bus} operations)

The seven institutional EV users surveyed were commercial fleet and bus operations in California and Arizona. The persons interviewed were program managers, energy specialists, fleet managers, a senior project manager for research and development, and a senior research engineer.

All survey respondents felt positively about their EV programs. All seven described positive experiences with their EVs and remarked that their customers were happy with them. None of the respondents had any acceptance or labor problems with their EV fleets. All seven institutional EV users perceived value in electric vehicles that could rapidly exchange batteries, four specifically pointing out that buses are very well-suited for rapid battery interchange. Six felt that $\mathrm{RBI}$ would enhance the value of their fleet vehicles and the service they provide. The best candidates for RBI were perceived to be vehicles that travel a fixed route.

Five respondents stated an interest in using automated battery exchange equipment in their operations. All seven would like to operate their own automated battery exchange systems. Six respondents saw an advantage in the standardization of quick-change battery modules and vehicle receptacles, and would conform to those standards, if established.

\section{Group 5: Private EV Owners or Potential Owners}

There were seven total survey respondents in this target group - six private EV owners and one potential EV owner. Their electric vehicles are mostly driven for commuting to work, in-town driving, and pleasure driving, over various terrain.

Of the seven respondents, six perceived value in electric vehicles that could rapidly exchange batteries. These six felt that rapid battery interchange would enhance the value of their vehicles, and that if $\mathrm{RBI}$ stations were available in the area in which the respondents expected to use their cars, this feature would make an electric vehicle feasible for their needs. In order for the respondent to consider the deployment or use of an $\mathrm{RB}$ system, the battery exchange must occur in a maximum of ten minutes for four of those surveyed, and under five minutes by the others.

The incremental cost respondents would be willing to pay for an EV with $\mathrm{RBI}$ capability varied from $2 \%$ to $10 \%$ of cost of vehicle, although specific figures of $\$ 2,000$, $\$ 5,000$ and $\$ 13,000$ were mentioned.

\section{CONCLUSIONS}

Vehicular battery interchange methods have been used for over 100 years to overcome the range and charging time limitations of EVs. Successful implementation is dependent upon significant infrastructure. In situations in which necessary infrastructure is available and range demands are high, rapid battery interchange appears to be an economical alternative to high-rate in-vehicle battery charging.

Safety issues related to electric vehicles are significant, but battery interchange capability does not appear to add significantly to the risk of operation compared with conventional EVs.

Survey results suggest that the majority of vehicle, equipment and battery manufacturers view the concept favorably but with skepticism. Near-term feasibility is greatest for applications in which external (not owned by the vehicle operator) infrastructure components are not required. Only fleet applications, with vehicles serviced from a central location meet this criteria. Among fleet applications, transit buses have been and will continue to be the favored deployment, since they operate on a fixed route with well-defined energy requirements and periodic visits to a common location.

\section{ACKNOWLEDGMENTS}

Support for this study was provided by the Pacific Gas and Electric Company, the California Energy Commission, and Loragen Corp. of San Luis Obispo, Calif. Graduate assistant Brian Mealy contributed much of the assessment of RBI safety. Prof. Ahmad Seifoddini of the Cal Poly Industrial Engineering Department contributed to the comparative economic analysis.

\section{CONTACT}

C. Arthur (Art) MacCarley is a Professor of Electrical Engineering at the California Polytechnic State University, and Principal Engineer for Loragen Corp., Transportation Electronics Group, San Luis Obispo, CA,. USA. Email: cam@ee.calpoly.edu or art@loragen.com.

\section{REFERENCES}

[AE92] "Government Action", Automotive Engineering, 1992.

[AP92] Associated Press. "Battery leak during electric car race hospitalizes 15", San Luis Obispo Telegram Tribune, April 28, 1992.

[APS92] MacLean, Richard. Interview conducted by author at the EPRI National 1992 Electric Vehicle Infrastructure Conference, San Francisco, Oct. 22, 1992.

[Auchard93] Auchard, Gary, Specialty Vehicle Manf. Corp., Los Angeles, CA. Interview conducted by author, January 1993. 
[Collie79.1] Collie, M.J. ed. Electric and Hybrid Vehicles. Appendix C - Batteries for Electric and Hybrid Vehicles. Noyes Data Corp., Park Ridge, New Jersey, 1979, pp. 369-71.

[Collie79.2] Collie, M. J. ed. ibid. p. 216, pp. 151-2.

[Collie79.3] Collie, M. J. ed. ibid. pp. 78,9.

[Collie79.4] Collie, M. J. ed. ibid. pp. 88.

[Collie79.5] Collie, M. J. ed. ibid. p. 558.

[Cooper81] Cooper, John F. and Homsy, Robert V. Development of the Aluminum-Air Battery for Electric Vehicle Applications. Electric Vehicle Development Group Fourth International Conference, London, England, distributed by SAE, Sept.1981.

[Crocker92] Crocker, Jean L. editor. General Motors Electric Vehicles Press Kit General Motors Corporation, Detroit, Mich.1992.

[Dietrich81] Dietrich, Eckhard O. Field Test Experience With Electric Vehicles. SAE paper No. 810489, contained in "Electric and Hybrid Vehicle Progress", SAE publication P-91, 1981.

[Dunning92] Dunning, John. Director of Delco Remy west cost operations. Personal correspondence, December, 1992.

[EVM92] Electic Vehicle Marketing Corporation. Product Information Brochure. P.O. Box 5478 Santa Barbara, CA 93150, 1992.

[Flink70] Flink, James J. America Adopts the Automobile, 1885-1910 MIT Press, Cambridge, Mass., 1970.

[Gambirasio83] Gambirasio, G., Ferreira, J.A., and Po, W. Refueling of Urban Electric Vehicles. Electric Vehicle Council Paper No. 8350, presented at EVC Expo, Detroit, MI, Oct. 4-6, 1983.

[GM92] General Motors Corp. Progress Report, Electric Vehicles, Summer 1992. General Motors Resource Center, Detroit, Mich. 1992.

[Green93] Green Car Journal (Electric Vehicle Industry Newsletter), Patents Intelligence ,Published by Green Car Media, February, 1993, p. 23.

[Gwyn84] Gwyn, Marion V. Battery Replacement System for Electric Vehicles US Patent No. 4,450,400 May 22, 1984.

[Hafer73] Hafer, Paul R. Electrically Driven Vehicles. US Patent No. 3,708,028 Jan. 2, 1973.

[Hamilton80.1] Hamilton, William. Electric Automobiles.. McGraw-Hill, N.Y., 1980, p. 173.

[Hamilton80.2] ibid. p. 77.

[Hamilton80.3] ibid. p. 16.

[Hane82] Hane, Dale R. Reciprocal Method and Apparatus for Transferring Vehicle Batteries. US Patent No. 4,342,533 Aug. 3,1982.

[Jones81] Jones, Clyde R. Convert Your Compact Car to Electric. Domus Books, Northbrook, III, 1981, p. 45.

[Kappei74] Kappei, Friedhelm. Mounting Support for the Battery Boxin the Carriage of Battery Driven Vehicles. US Patent No. 3,838,745Oct. 1, 1974.
[Karen79] Karen, T. Designing Purpose Built Electric Vehicles - The Total Energy Required for Manufacture and Use. Electric Vehicle Development Group Third International Conference, London, England, distributed by SAE, Nov. 1979.

[Klink81] Klink, Rainer. Installation for the Accommodation of an Interchangeable Energy-Storage Device in a Motor Vehicle. US PatentNo. 4,258,816 Mar. 31, 1981.

[MacCarley94] Final Project Report, Rapid Battery Interchange for Electric Vehicles, Phase 1, Part A: Analysis and Feasibility Assessment. Prepared for Pacific Gas and Electric Company. Cal Poly, San Luis Obispo, 1993.

[MacCarley95] Final Project Report, Rapid Battery Interchange for Electric Vehicles, Phase 1, Part B: Planning and Preliminary Design for Demonstration Project. Report prepared for California Energy Commission. Cal Poly, San Luis Obispo, 1995.

[Mader91] Mader, Gerald H. ed. EVDC Information Network Newsletter, "Nissan Quick Charging System", Electric Vehicle Development Corp., Cupertino, California, Sept. 1991, p. 2.

[MATSI92] Putt, Ronald A., Merry, G.W. and Swaroop, Robert B. Zinc-Air Range Batteries For Electric Vans. EPRI Project ReportRP2415-28, November 1991.

[McGeehin79] McGeehin, P. and Dell, R.M. A Review of the Energy Casefor Electric Vehicles. Electric Vehicle Development Group Third International Conference: Resources for Electric Vehicles. Peregrinus, November 1979.

[Palvoelgyi90] Palvoelgyi, S. and Stangl, PK. Crashworthiness of the Electric G-Van. Contained in Electric Vehicle Technology, SAE publication 1-56091026-7, pp. 99-105, February 1990.

[Rahders92] Rahders, Richard R. Rapid Battery Swaps in EVs at the Phoenix S \& E 500 4/92, and Performance Comparisons to Some Non-Swap Cars. Video tape by Electro Automotive Information Services, Felton, CA, September 23, 1992.

[Risser92.1] Risser, Roland J. ed. EVAA Information Network Newsletter. Electric Vehicle Association of the Americas, Cupertino, Calif., Vol. 9, Nov/Dec 1992, p. 4.

[Risser92.2] Risser, Roland J. ed. EVAA Information Network Newsletter. Electric Vehicle Association of the Americas, Cupertino, Calif., Vol. 8, Oct. 1992, p. 3.

[Wakefield94] Wakefield, Ernest Henry. History of the Electric Automobile: Battery-Only Powered Cars. SAE Publications, Warrendale, PA, 1994.

[Weeks78] Weeks, R. A Refueling Infrastructure for Electric Cars. TRRL Laboratory Report 812, Transport and Road Research Laboratory, Crowthorne, Berkshire, England, 1978.

[Wyczalek92] Wyczalek, F.A., Earle, M., Sloan, D.E., Standish, F., and Tetherow, J. Propulsion Technology: an Overview. Society of Automotive Engineers, Warrendale, PA., July 1992.

[Ziganti92] Ziganti, Alison C. and Brown, Paul J., ed. EVAA Information Network Newsletter. Electric Vehicle Association of the Americas, Cupertino, Calif., Vol. 4, May 1992, p. 2. 